\title{
Times of Detection of Drugs of Abuse in Saliva: Study of Arrested Population
}

Amparo Arroyo*, Agustí Mora, Marta Sanchez, María Barbal and Mariona Palahi

Forensic Laboratory of the Legal Medicine Institute of Catalonia Barcelona, Spain

\begin{abstract}
Aim: Detection of drugs of abuse is interesting in legal procedures. The aims of the study were: 1: Evaluating the detection time of drugs of abuse in saliva in an arrested population, drugs consumers that are taken into judicial custody in a maximum time of 72 hours from their detention. 2- Verifying analytical results with self reported reference of the subjects.

Participants: 50 oral fluid samples coming from arrested people that are taken into judicial custody in police officer's courts of the city of Barcelona. The study was carried out in the Laboratory of the Institute of Legal Medicine of Catalonia. The design study was a cross sectional study. Drug tested were: cocaine, amphetamines and related compounds, cannabis and opiates. The time of previous consumption was of 1-3 days.

Measurements: The oral fluid samples were analysed by gas- chromatography-mass spectrometry.

Findings: Positive results were obtained in $40 \%$ of the samples. Cocaine was detected in the $73.9 \%$ of positive results to this drug. Cannabis was detected in the $28.5 \%$, Opiates was detected in the $23,1 \%$. Amphetamines were not detected.
\end{abstract}

Conclusions: It is important to stand out the high rate of cocaine positive results in relation with the time passed and abstinence consumption of 1-3 days. Oral fluid may be a good sample for cocaine detection in drug consumers.

Keywords: Forensic sciences; Forensic toxicology; Drugs of abuse; Drug analysis; Oral fluid analysis; Legal medicine

\section{Introduction}

At present detection of drugs of abuse is of interest in different fields of legal medicine. Among others, saliva is a fluid that has increased in the last years for this purpose and the publication of texts as the Proposed Revisions to Federal Mandatory Guidelines for Workplace Drug Testing Programs emphasizes its acceptance [1]. The advantage of this fluid is not being an invasive sample, easy to obtain and difficult to tamper with or to forge. In a progressive and routine form the saliva is analysed coming from samples of the workplace, criminal justice and rehabilitation centres. It is necessary to add the kits of detection that begun to be tested in 1983 on side of highways, to detect drivers who were driving under the influence of the drugs [2].

Schramm et al. [3] had provided an early review on detection times of drugs and early studies pre 1990s. Other reviews on the testing for drugs of abuse in saliva also exist [4].

Toxicologists are frequently asked about the duration of detection times of drugs, but is difficult to get approval for this kind of studies because illicit products have to be given to healthy volunteers and doses administered are low compared with street doses.

The aims of the study were: a) to evaluate detection times of drugs of abuse in saliva in a drug abuse population, arrested people who are taken into judicial custody. Drugs tested were; cannabis, cocaine, amphetamines, methamphetamines and related compounds (MDMA and MDEA) and opiates. Qualitative analysis was carried out. The time between the detention of arrested people and time of collecting saliva sample was 1-3 days. Oral fluid were collected from 50 individuals and analyzed by gas-chromatography-mass-spectrometry (GC-MS). b) To compare analytical results with the self-referred information by the arrested people related to the time on the last consumptions of toxics.

\section{Material and Methods}

\section{Design of the study: cross-sectional study}

Size of the sample: 50 oral fluid samples coming from arrested people that are taken into judicial custody in police officer's courts of the city of Barcelona. The study was carried out in the Laboratory of the Institute of Legal Medicine of Catalonia.

Selection of the sample: The participation was requested to the detainees that were addicted to drugs that used the right to be looked after by a forensic doctor according to the legal spanish normative [5]. All subjects had a history of chronic drugs abuse consumption. Inclusion criteria included self-reported use of smoked, inhaled or intravenous drugs at least for six months prior to the detention. The participants provided informed consent. Times of abstention consumption could not be accurately established, but ranged from 1-3 days during staying in the police setting. Additional information was gathered relative to the sex and age of the participants.

Methods: Obtaining of the sample: the sample of saliva was obtained directly by spitting in a polypropylene tube. Saliva flow was not stimulated. Following collection oral fluid was aliquoted into cryotubes and frozen at $-20^{\circ}$ until analysis.

*Corresponding author: Amparo Arroyo Fernández, Institut de Medicina Legal de Catalunya, Gran Vía de les Corts Catalanes 111, Edif G 5a Planta, 08114 Barcelona, Spain, Tel: +34935548343; E-mail: amparo.arroyo@xij.gencat.cat

Received Januray 18, 2011; Accepted February 14, 2011; Published February 17, 2011

Citation: Arroyo A, Mora A, Sanchez M, Barbal M, Palahi M (2011) Times of Detection of Drugs of Abuse in Saliva: Study of Arrested Population. J Forensic Res 2:114. doi:10.4172/2157-7145.1000114

Copyright: (C) 2011 Arroyo A, et al. This is an open-access article distributed unde the terms of the Creative Commons Attribution License, which permits unrestricted use, distribution, and reproduction in any medium, provided the original author and source are credited. 
Descriptive analysis of categorical variable and media, range and standard deviation of quantitative variable were done. Identification of analytes were done by GC-MS. Quantification of analytes was not done.

Sample preparation: Sample preparation consisted in the addition of $1 \mathrm{ml}$ of oral fluid, without centrifugation, and the $\mathrm{pH}$ was readjusted with $1 \mathrm{ml}$ of phosphate buffer $(\mathrm{pH}=6)$. Once the $\mathrm{pH}$ is readjusted, $20 \mu \mathrm{l}$ of d3-cocaine, d3-6-MAM, d5-amphetamine, d9-methamphetamine and $\Delta^{9}$ THC are added for a final concentration of $10 \mu \mathrm{g} / \mathrm{ml}$.

Sample was homogenised for $10 \mathrm{~min}$. and transferred in a Toxitube $\mathrm{A}^{\oplus}$ which was waved for $10 \mathrm{~min}$ and centrifuged $(3500 \mathrm{rpm}$ for 10 $\mathrm{min})$. The organic phase was extracted, evaporated to dryness under nitrogen and derivatized with $40 \mu \mathrm{l}$ of BSFTA (N,O-bis(trimethylsilyl) trifluoroacetamide) -TMCS (trimethylchlorosilane) at $80^{\circ} \mathrm{C}$ for $20 \mathrm{~min}$ for $\Delta^{9}$-THC and 6-MAM or PFPA for amphetamines and methamphetamines at $50^{\circ} \mathrm{C}$ for $40 \mathrm{~min}$.

\section{Gas cromatography-mass spectrometry confirmation}

Chemicals and materials: Methanolic solutions with a concentration of $1 \mathrm{mg} / \mathrm{mL}$ of cocaine, $\Delta^{9}$-tetrahydrocannabinol ( $\Delta^{9}$-THC), amphetamine, methamphetamine, dl-3, 4-methylendioximethamphetamine (dl-3, 4-MDMA), dl-3, 4-methylendioxiethampheta-mine (dl-3, 4-MDEA) and 6-monoacetylmorphine (6-MAM) were purchased from Alltech-Applied Science (State College, PA, USA).

For derivatization of $\Delta^{9}$-THC and 6-MAM, BSTFA and TMCS used as BSTFA $+1 \%$ TMCS were provided by Supelco (Bellefonte, PA, USA) and 2,2,3,3,3-Pentafluoropropionic acid (PFPA) by Merck KGaA (Darmstadt Germany). Phosphate buffer $(0.1 \mathrm{M})$ was prepared from $\mathrm{NaH}_{2} \mathrm{PO}_{4}$ and adjusted to $\mathrm{pH} 6.0$ with $\mathrm{NaOH} 0.1 \mathrm{M}$.

GC/MS-MS conditions: A Varian Inc. (Palo Alto, USA) 3800 gas chromatograph coupled to a 4000 mass selective ion trap detector (MSD) operating in electron impact mode was used for analysis (GC/MS-MS). The gas chromatographic column was 5\% phenyl-95\% methyl silicone DB-5, $0.25 \mathrm{~mm}$ ID, $0.25 \mu \mathrm{m}$ thickness, $30 \mathrm{~m}$ length (Varian factor Four Capillary Column) and the injection temperature was $250^{\circ} \mathrm{C} .2 \mu \mathrm{l}$ of the sample were injected in split-less. The oven was programmed from $90^{\circ} \mathrm{C}$ for 1 minute; ramped at $20^{\circ} \mathrm{C} / \mathrm{min}$ to $240^{\circ} \mathrm{C}$; then ramped at $5^{\circ} \mathrm{C} / \mathrm{min}$ to $300^{\circ} \mathrm{C}$ where it remained for two minutes. The transfer line was held at $280^{\circ} \mathrm{C}$. The total run time was $23.5 \mathrm{~min}$. Detection was done operating in MS/MS. Details of the procedure of detection applied are shown in Table 1.

The different substances and ions used in identification by MS-MS are shown in Table 2. The detection limits (LOD) and quantification limits (LOQ) values used in the GC-MS/MS confirmation and LOD and LOQ established for GC/MS-MS are shown in Table 3. No attempts were made to determine quantitative values in positive results samples.

\begin{tabular}{|l|l|l|l|}
\hline Drug Target & Ionization & Waveform Type & $\begin{array}{l}\text { Excitation } \\
\text { Width (V) }\end{array}$ \\
\hline Amphetamine-PFP & El $^{\text {a }}$ & Non resonant & 64.0 \\
\hline Methamphetamine-PFP & EI & Non resonant & 60.0 \\
\hline MDMA-PFP & EI & Non resonant & 60.0 \\
\hline MDEA-PFP & El & Non resonant & 57.0 \\
\hline Cocaine & El & Non resonant & 45.0 \\
\hline$\Delta^{9}$-THC-TMS & EI & Non resonant & 61.0 \\
\hline 6-MAM-TMS & El & Resonant & 1.0 \\
\hline
\end{tabular}

Table 1: Drug targets and procedures used in GC-/MS/MS.

\begin{tabular}{|l|l|l|l|}
\hline Drug Target & tr $(\mathbf{m i n})$ & $\begin{array}{l}\text { Precursor ion } \\
(\mathbf{m} / \mathbf{z})\end{array}$ & $\begin{array}{l}\text { Qualifier ions } \\
\mathbf{( m / z )}\end{array}$ \\
\hline Amphetamine-PFP & 5.92 & 190 & $118,91,119$ \\
\hline Methamphetamine-PFP & 6.81 & 204 & 160,119 \\
\hline MDMA-PFP & 10.53 & 204 & 160,161 \\
\hline MDEA-PFP & 11.07 & 218 & $190,146,163$ \\
\hline Cocaine & 16.85 & 182 & $150,82,122$ \\
\hline$\Delta^{9}$-THC-TMS & 17.43 & 386 & $371,315,330$ \\
\hline 6-MAM-TMS & 20.11 & 399 & $356,340,287$ \\
\hline
\end{tabular}

Table 2: Drug targets, retention times (tr) and ions selected for each studied drug.

\begin{tabular}{|l|l|l|}
\hline \multirow{2}{*}{ Drug Target } & GC/MS-MS & \\
\cline { 2 - 2 } & LOD $\mathbf{( n g} / \mathbf{m l})$ & LOQ $\mathbf{( n g} / \mathbf{m l})$ \\
\hline Amphetamine-PFP & 5 & 20 \\
\hline Methamphetamine-PFP & 5 & 20 \\
\hline MDMA-PFP & 5 & 20 \\
\hline MDEA-PFP & 5 & 20 \\
\hline Cocaine & 2.5 & 10 \\
\hline$\Delta^{9-T H C-T M S ~}$ & 2.5 & 10 \\
\hline 6-MAM-TMS & 5 & 20 \\
\hline
\end{tabular}

Table 3: Detection limits (LOD) and detection quantification limits (LOQ) values for GC-MS/MS analysis.

\begin{tabular}{|c|c|c|c|c|c|}
\hline Case & $\mathrm{t}$ & Analyte & Case & $\mathrm{t}$ & Analyte \\
\hline $\mathrm{N}^{\circ} 2$ & 1 & Cocaine + 6 MAM & $N^{0} 21$ & 2 & Codeine \\
\hline$N^{\circ} 3$ & 3 & Cocaine & $N^{0} 23$ & 1 & $\Delta^{9}$ tetrahydrocannabinol \\
\hline$N^{\circ} 4$ & 1 & Cocaine & $N^{\circ} 27$ & 3 & Cocaine \\
\hline$N^{0} 6$ & 3 & Cocaine & $N^{0} 28$ & 3 & Cocaine \\
\hline$N^{\circ} 9$ & 2 & Cocaine +codeine & $N^{0} 29$ & 2 & Cocaine+ecgonidine-metilester \\
\hline No10 & 2 & Cocaine & $N^{\circ} 30$ & 2 & Cocaine $+\Delta^{9}$ tetrahydrocannabinol \\
\hline No11 & 2 & Cocaine & $N^{0} 31$ & 3 & Cocaine $+\Delta^{9}$ tetrahydrocannabinol \\
\hline No15 & 2 & Cocaine & $N^{0} 32$ & 3 & Cocaine \\
\hline$N^{0} 18$ & 2 & Cocaine & $N^{0} 36$ & $<1$ & Cocaine \\
\hline$N^{\circ} 20$ & 2 & $\Delta^{9}$ tetrahidrocannabinol & $N^{\circ} 48$ & 2 & Cocaine \\
\hline
\end{tabular}

Table 4: Analytes confirmed by CG-MS in positive results $(\mathrm{N}=20)$.

\begin{tabular}{|l|l|l|}
\hline Total $\mathrm{N}=50$ & $\begin{array}{l}\text { Self reported Drugs } \\
\text { Consumption }\end{array}$ & Drugs Confirmed Analysis CG-MS \\
\hline Cocaine & $\mathrm{N}=23$ & $\mathrm{~N}=17$ \\
\hline Cannabis & $\mathrm{N}=14$ & $\mathrm{~N}=4$ \\
\hline Amphetamines & $\mathrm{N}=1$ & ${ }^{*} \mathrm{ND}$ \\
\hline Opiates & $\mathrm{N}=13$ & $\mathrm{~N}=3$ \\
\hline Methadone & $\mathrm{N}=14$ & $\mathrm{~N}=13$ \\
\hline
\end{tabular}

*ND: not detected

Table 5: Analytical Results and self reported consumption of drugs.

\section{Results}

Middle age of subjects was 31, 6 years (range 38, max. 56, and min 18, SD 8.5).

Male gender was predominant. Female gender was $12 \%$ of the sample. Positive results to drugs were confirmed in $40 \%$ of the sample, 20 cases. In these cases drugs were confirmed for at least one analyte $80 \%$, and two drugs were found in $20 \%$ of this group.

Cocaine was the principal analyte confirmed, 73, 9\% although cocaine and ecgonidine- metilester was detected in two cases of this group. $\Delta^{9}$ Tetrahydrocannabinol was confirmed in $28.5 \%$. Opiates were confirmed in $23,1 \%$ of the individuals who referred consumption (one case 6- MAM, 2 cases codeine) Amphetamines were not detected. Abstinence referred drugs consumption times in the 20 positive cases results were $20 \%$ one day, $50 \% 2$ days, $30 \%$ three days. Cases and results positive to drugs are exposed in Table 4.

Results comparing self reported consumption cases and GCMS confirmed cases are exposed in Table 5 and Figure 1. Methadone 


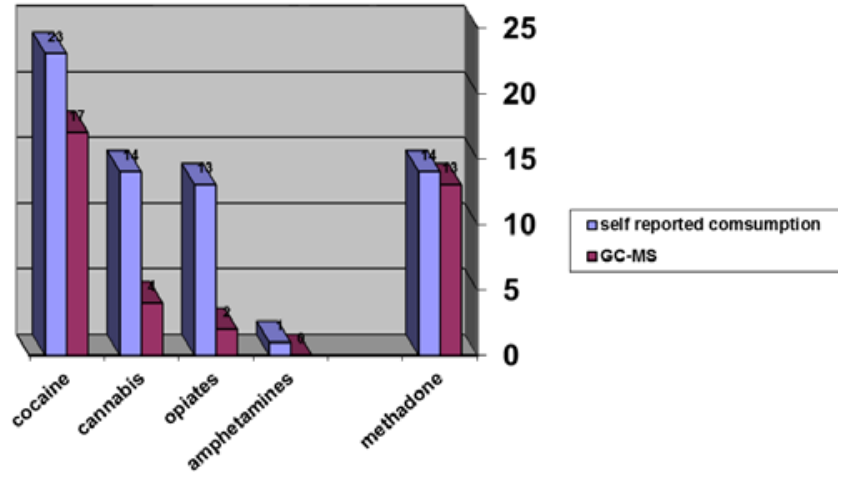

Figure 1: Comparison of results between self reported consumption and chromatography analysis $(\mathrm{N}=50)$.

was found in the $92.8 \%$ of the subjects who were in the maintenance program, although this drug was not specifically scheduled for detection.

\section{Discussion}

The most important information of our results is the detection of cocaine in a high percentage of the sample, after an interval of abstention from consumption among 1-3 days, 17 cases. Only a few investigators have evaluated the pharmacokinetics of orally administered cocaine and even less has been published about the pharmacokinetics of chronic cocaine administration $[6,7,8]$. These results do not match with previous data known about the rapid decrease of cocaine and acceptance that drugs in saliva follows the same metabolic course that in blood. Some studies indicate that the cocaine in saliva can be detected up to 17 hours with a correlation of 3 with the plasma $[9,10]$. Nevertheless, it is important to emphasize some works where longest times of detection in chronic consumers are described. Cone and Weddington [11] provided evidence of prolonged excretion of cocaine in oral fluid specimens collected from heavy cocaine users during abstinence and postulated that cocaine can be excreted in low concentration over long period of time. Cocaine is a lipophilic compound that can be stored in bodily tissues to a greater extent than the more water soluble metabolite benzoilecgonine, following repeated dosing and result in accumulation in bodily tissues. It is likely slower elimination phase for the drug and extended elimination times upon cessation of use. Although cocaine has an extremely short half-life of approximately 1 hour, accumulation in tissues could conceivably result in prolongation of effects, amelioration of withdrawal, and alteration of detection times. These authors indicate an average life of elimination of cocaine in saliva between 21.6-110.4 h. In chronic users even it can reach 10 days with a LOD $0,5 \mathrm{ng} / \mathrm{ml}$. Other authors agree with this statement [7]. It remains unclear how repeated dosing alters or prolongs detection times.

Our population belongs to a group of drug dependent chronic consumers and it would justify the prolongation of time of detection of cocaine what agrees with data published by the mentioned authors.

Only confirmation of the cannabis was obtained in 4 of 14 cases where a previous consumption was reported. According to Niedbala the cannabis can be detected in saliva up to 30 hours after the consumption to certain doses [12]. According to other authors is detected between 2-10 hours [13,14]. Laloup et al. [15] found good correlation between the THC in saliva and plasma in 139 subjects what agrees with other publications though protocols of analysis and values of cut-off established in every study can be different and may affect the results [16].

Only one case of amphetamines consumption was revealed but not confirmed in the analytical chromatographic study. Amphetamines in saliva, since they are basic drugs, can present higher concentrations than in plasma [17]. Actually very sensitive methods have been published for its detection and quantification [18]. Having had only one sample we cannot get conclusions. Opiates were only confirmed in 3 of 13 cases although codeine was the analyte found in two cases. The detection of opiates can arrive up $24 \mathrm{~h}$, according to administered dose [19] though Speckl et al. point out that time of detection can be situated between 1-4 days [20].

In our sample we have detected methadone in 13 of 14 self reported consumption cases. It was not one of our objectives because of methadone analysis is not so routinely investigated since its administration belongs to sanitary established programs.

Detection times are generally determined in drug administration studies performed with a small number of individuals who are housed in a close setting. Most frequently detection times are determined in studies in which a single dose is administered. Some caution is needed because of inherent limitations on detection times based in these studies that may not be truly representative of frequent drugs users. The detection time is influenced by many factors: the dose that was taken, the preparation and route of administration, acute versus chronic use, the choice of the matrix, the detection time or cut-off of the analytical technique, the nature of the molecule or the metabolite sought, the ph and concentration of oral fluid and the interindividual variation in metabolism [21]. Unfortunately there is a paucity of data on drug detection times following repeated use. These studies, under controlled conditions are exceedingly difficult and expensive to perform and few studies have focused on the detection time. Volunteers' studies are based in controlled administration in subjects imprisoned or admitted for detoxification. The work that gathers a good number of experimental studies in volunteers' saliva is Drummer's review that describes 23 studies [22]. The analysis were carried out after short intervals of time from the administration of the compound, up to the capture of the sample of saliva; the detection of the drugs was not evaluated in long times.

The limitations of our study and of others published on the matter are the difficulties of carrying out controlled studies in a big sample and the scanty quantity of sample that is possible to obtain, since many drugs originate dryness of mouth.

Secondly confusion can exist in the information reported by the subjects about drugs abuse consumption. Concordance was not full between the self reported data and the analytical results. In relation with cocaine, in 3 detected cases the consumption was not referred, and in 8 cases where the consumption was referred the results were not confirmed.

In our study it was not possible to specify the quantities of administered substances which is controlled in the experimental studies. For that reason quantitative analysis of these substances in oral fluid was not done and our objective was only to confirm a qualitative result.

In conclusion detection times related to opiates and cannabis are not reliable in a period of 1-3 days but cocaine time detection may be longer and detectable in chronic drugs users, which agrees with other published data but a larger sample must be investigated in order to corroborate our results. 
Citation: Arroyo A, Mora A, Sanchez M, Barbal M, Palahi M (2011) Times of Detection of Drugs of Abuse in Saliva: Study of Arrested Population. J Forensic Res 2:114. doi:10.4172/2157-7145.1000114

\section{References}

1. Department of Health and Human Services. Proposed revisions to mandatory Guidelines for federal Workplace Drug Testing Programs. United States. Federal Register 2004. 69: 19673-19732.

2. Verstraete A (2005) Oral fluid testing for drivers under the influence of drugs: history, recent progress and remaining challenges. Forensic Sci Int 150: 143150.

3. Schramm W, Smith RH, Craig PA, Kidwell DA (1992) Drugs of abuse in saliva: a review. J Anal Toxicol 16: 1-9.

4. Kidwell DA, Holland JC, Athanaselis S (1998) Testing for drugs of abuse in saliva and sweat. J Chromatogr B Biomed Sci Appl 713: 111-135.

5. Orden Ministerial 16 de Junio de1997. BOE. Madrid 1997.

6. Jufer RA, Wstadik A, Walsh SL, Levine BS, Cone EJ (2000) Elimination of cocaine and metabolites in plasma saliva, and urine following repeated ora administration to human volunteers. J Anal Toxicol 24: 467-477.

7. Jufer R, Walsh SL, Cone EJ, Sampson-Cone A (2006) Effect of repeated cocaine administration on detection times in oral fluid and urine. J Anal Toxicol 30: $458-462$

8. Verstraete AG (2004) Detection times of drugs of abuse in blood, urine and oral fluid. Drug Monit 26: 200-205

9. Cone EJ, Hillisgrove M, Darwin WD (1994) Simultaneous measurement of cocaine, cocaethylene, their metabolites and crack pyrolisis products by gas chromatography spectrometry. Clin Chem 40: 1299-305.

10. Jenkins AJ, Oyler JM, Cone EJ (1995) Comparison of heroin and cocaine concentrations in saliva with concentrations in blood and plasma. J Anal Toxicol 19: 359-374.

11. Cone EJ, Weddington WW Jr (1989) Prolonged occurrence of cocaine in human saliva and urine after chronic use. J Anal Toxicol 13: 65-68.

12. Niedbala RS, Kardos KW, Fritch DF, Kardos S, Fries J, et al. (2001) Detection of marijuana use by oral fluid and urine analysis following single-dose administration of smoked and oral marijuana. J Anal Toxicol 25: 289-303.

13. Maseda C, Hama K, Fukui Y, Matsubara K, Takahashis S, et al. (1986) Detection of delta $-9-$ THC in saliva by capillary GC/ECD after marihuana smoking. Forensic Sci Int 32: 259-260.

4. O'kane CJ, Tutt DC, Bauer LA (2002) Cannabis and driving: a new perspective. Emerg Med 14: 296-303.

15. Laloup M, Ramírez M, Wood M, Boeck G, Mas V, et al. (2006) Correlation of d 9 tetrahidrocannabinol concentration determined by LC-Ms-MS in oral fluid and plasma from impaired drivers and evaluation of the on-site Drager Drug Test. Forensic Sci Int 161: 175-179.

16. Toennes SW, Kauert GF, Steinmeyer S, Moeller MR (2005) Driving under the influence of drug-evaluation data of drugs in oral fluid, serum and urine and correlation with impaired symptoms. Forensic Sci Int 152: 149-155.

17. Schepers R, Oyler J, Joseph R, Cone E, Moolchan E, et al. (2003) Methamphetamine and amphetamine pharmacokinetics in oral fluid plasma after controlled oral methamphetamine administration to human volunteers Clin Chem 49: 121-132.

18. Concheiro M, de Castro A, Quintela O, Lopez Rivadulla M, Cruz A (2005) Determination of MDMA, MDA, MDEA and MBDB in oral fluid using high performance liquid chromatography with native fluorescence detection. Forensic Sci Int 150: 221-226.

19. Cone EJ (1990) Testing human hair for drugs of abuse. Individual dose and time profiles of morphine and codeine in plasma, saliva, urine, and beard compared to drug-induced effects on pupils and behavior. J Anal Toxicol 14: 1-7.

20. Speckl I, Aviac. J, Guder W, Von Meyer L, Zilker T (1999) Opiate detection in saliva and urine--a prospective comparison by gas chromatography-massspectrometry. J Toxicol Clin Toxicol 37: 441-445.

21. Vandevenne $M$, Vandenbussche $H$, Verstraete $A$ (2000) Detection time of drugs of abuse in urine. Act Clin Belg 55: 323-333.

22. Drummer $\mathrm{OH}$ (2005) Review:Pharmacokinetics of illicit drugs in oral fluid Forensic Sci Int 150:133-142. 